\title{
La terapia génica con el activador de plasminógeno tipo urocinasa media la regeneración hepática
}

\author{
Ana Sandoval-Rodríguez, ${ }^{1}$ Alejandra Meza-Ríos, ${ }^{2}$ Mayra Mena-Enríquez, ${ }^{3}$ y Juan Armendáriz-Borunda1,2* \\ ${ }^{1}$ Instituto de Biología Molecular y Terapia Génica, Departamento de Biología Molecular y Genómica, Universidad de Guadalajara, Guadalajara, \\ Jalisco; ${ }^{2}$ Tecnológico de Monterrey, Escuela de Medicina y Ciencias de la Salud, Guadalajara, Jalisco; ${ }^{3}$ Departamento de Ciencias de la Salud, \\ CU Tonalá, Universidad de Guadalajara, Jalisco. México
}

\section{Resumen}

Antecedentes y objetivos: La terapia génica empleando el activador de plasminógeno tipo urocinasa (huPA) ha demostrado que induce la degradación de matriz extracelular, la proliferación de hepatocitos y el restablecimiento de la funcionalidad tisular en modelos de cirrosis hepática. Fisiológicamente, el uPA activa la conversión del plasminógeno en plasmina, lo que conlleva, dependiendo del órgano, una trombólisis o a degradación de la matriz extracelular. El objetivo de este estudio fue comparar el efecto regenerador de la terapia génica con adenovirus codificando la forma silvestre (huPA), así como su isoforma truncada ( $\triangle$ huPA) en animales sanos y cirróticos. Además, se valoraron los posibles efectos adversos sobre la coagulación. Métodos: Se administró $6 \times 10^{11} \mathrm{pv} / \mathrm{kg}$ del Ad-huPA o Ad- $\triangle$ huPA a ratas Wistar macho sanas o con cirrosis por intoxicación crónica con tetracloruro de carbono $\left(\mathrm{CCl}_{4}\right)$ vía vena ilíaca. El sacrificio fue al día 2, 4 o 6 postratamiento. Se evaluó la fibrosis hepática, la expresión de antígeno nuclear de proliferación celular y niveles séricos de alanina aminotransferasa (ALT) y aspartato aminotransferasa (AST), y marcadores de coagulación. Resultados: Al día 6 postratamiento se alcanzó una reversión de fibrosis del 48.7-41.5\%. Los niveles de AST y ALT no cambiaron en animales cirróticos tratados con $\triangle$ huPA, pero aumentaron en animales sanos comparados con el control sano no tratado. La proliferación aumenta en animales sanos y cirróticos con ambas isoformas del transgén. No se observaron efectos adversos en la coagulación en el grupo $\triangle$ huPA y para el día 6 habían desaparecido en el grupo huPA. Conclusiones: La terapia génica con Ad-uPA y Ad- $\triangle$ huPA favorece la proliferación celular en animales cirróticos, sin efectos secundarios importantes.

PALABRAS CLAVE: Terapia génica. Adenovirus. Plasminógeno tipo urocinasa. Cirrosis.

\section{Gene therapy wuth urokinase-type plasminogen activator regenerates liver tissue}

\section{Abstract}

Background and objectives: Gene therapy using urokinase-type plasminogen activator (uPA) has been shown to induce extracellular matrix degradation, hepatocyte proliferation and liver tissue function restoration in liver cirrhosis models. Physiologically, UPA activates plasminogen conversion to plasmin, which leads, depending on the organ, to thrombolysis or extraceIlular matrix degradation. The purpose of this study was to compare the regenerative effect of gene therapy with adenoviruses encoding wild-type UPA (huPA), as well as its truncated isoform ( $\triangle$ huPA), in healthy and cirrhotic animals. In addition, possible adverse effects on coagulation were assessed. Methods: $6 \times 10^{11} \mathrm{vp} / \mathrm{kg}$ of Ad-huPA or Ad- $\Delta$ huPA were administered via the iliac vein to healthy male Wistar rats or to male Wistar rats with cirrhosis induced by chronic poisoning with carbon tetrachloride (CC/4). The animals were sacrificed at day 2, 4 or 6 post-treatment. Liver fibrosis, proliferating cell nuclear antigen expression, alanine aminotransferase (ALT) and aspartate aminotransferase (AST) serum levels and coagulation markers were evaluated. Results: On day 6 post-treatment, a fibrosis reversal of 48.7-41.5\% was achieved. AST and ALT levels did not

Correspondencia:

*Juan Armendáriz-Borunda

E-mail: armendbo@cucs.udg.mx
Gac Med Mex. 2021:157:525-532

Disponible en PubMed

www.gacetamedicademexico.com

0016-3813/@ 2021 Academia Nacional de Medicina de México, A.C. Publicado por Permanyer. Este es un artículo open access bajo la licencia CC BY-NC-ND (http://creativecommons.org/licenses/by-nc-nd/4.0/). 
change in cirrhotic animals treated with $\triangle$ huPA, but showed an elevation in healthy animals. Cell proliferation increased in healthy and cirrhotic animals with both transgene isoforms. No coagulation adverse effects were observed in the $\triangle$ huPA group, and by day 6, they had disappeared in the huPA group. Conclusions: Gene therapy with Ad-huPA and Ad- $\triangle$ huPA favors cell proliferation in cirrhotic animals, without important side effects.

KEY WORDS: Gene therapy. Adenovirus. Urokinase plasminogen activator. Cirrhosis.

\section{Introducción}

La fibrosis hepática y la cirrosis representan la vía final común de varias enfermedades del hígado. Ocasionadas por varias etiologías, la fibrosis y cirrosis hepática representan una de las primeras causas de morbilidad y mortalidad del mundo. En México las enfermedades hepáticas se encuentran entre las primeras causas de muerte en edad productiva. La fibrosis es el resultado de una acumulación excesiva de componentes de matriz extracelular (MEC) como colágenas y fibronectina, secretadas por miofibroblastos en respuesta al daño celular crónico'. La respuesta inflamatoria puede perpetuarse y finalmente favorecer el proceso de fibrosis y llevar a un estado patológico con pérdida de la función del hígado y la formación permanente de una cicatriz².

El plasminógeno es una glucoproteína que circula en el plasma como zimógeno, siendo precursor inactivo de la plasmina ${ }^{3}$. La plasmina es una proteasa que escinde varias proteínas de MEC, incluyendo fibronectina, factor von Willebrand, laminina, trombospondina y colágena tipo IV. Juega un papel importante en la activación de varias metaloproteinasas de matriz extracelular (MMP) como pro-MMP-1, pro-MMP-3, pro-MMP-9 y pro-MMP-2, las cuales degradan otros constituyentes de MEC ${ }^{4,5}$. La plasmina puede afectar la actividad de citocinas y factores de crecimiento, como el factor de crecimiento transformante beta, que influye en la composición y degradación de la matriz extracelular de manera directa o indirecta, siendo la principal citocina profibrogénica ${ }^{4}$.

Las terapias antifibróticas tienen el objetivo de inhibir el depósito de proteínas de MEC y/o acelerar su degradación. Basado en lo anterior, la terapia génica utilizando genes huPA y $\triangle$ huPA han demostrado ser efectivos como terapias antifibrogénicas en modelos experimentales de cirrosis hepática. Estudios previos, de nuestro grupo y otros, han demostrado que huPA y $\triangle$ huPA ${ }^{6,7}$ estimulan la proliferación hepática en modelos cirróticos, favoreciendo el restablecimiento de la funcionalidad tisular. El objetivo del presente trabajo fue comparar el efecto de huPA y $\triangle$ huPA tanto en hígados cirróticos como sanos; en marcadores de regeneración celular, grado de fibrosis y funcionalidad hepática, y evaluar si el tratamiento con huPA presenta efectos adversos en la coagulación.

\section{Material y métodos}

\section{Modelo animal y administración de tratamiento}

Se intoxicaron ratas Wistar macho ( $n=5 / g r u p o$, 120 g peso) con tetracloruro de carbono $\left(\mathrm{CCl}_{4}\right)$ i.p. durante ocho semanas. Un grupo de cinco ratas no intoxicadas sirvieron como control sano. En animales sanos y cirróticos, se administró $6 \times 10^{11} \mathrm{pv} / \mathrm{kg}$ de Ad-huPA o Ad- $\triangle$ huPA, a través de la vena ilíaca al final del régimen de intoxicación con $\mathrm{CCl}_{4}$. Los adenovectores se titularon como se describió anteriormente ${ }^{7,8}$. El sacrificio se realizó al día 2, 406 postratamiento, Secciones representativas de los cinco lóbulos de hígado se recolectaron y se mantuvieron congeladas $\left(-70^{\circ} \mathrm{C}\right)$ hasta su análisis. Durante el protocolo las ratas recibieron cuidados de acuerdo con la Norma Oficial Mexicana NOM-062-ZOO-1999.

\section{Determinación del grado de fibrosis}

Para evaluar el grado de fibrosis hepática se extrajo y fijó tejido hepático en paraformaldehído al 10\%, seguido de deshidratación en etanol y embebido en parafina. Secciones de $5 \mu \mathrm{m}$ de espesor se tiñeron con tricrómico de Masson. El porcentaje de fibrosis se determinó en 30 campos al azar utilizando un analizador de imágenes (Image-ProPlus 6.0).

\section{Determinación de proliferación celular por inmunohistoquímica contra PCNA}

La proliferación celular fue determinada por inmunohistoquímica contra el antígeno nuclear de proliferación celular (PCNA). Secciones de hígado fueron incubadas con anticuerpo monoclonal contra PCNA diluido 1:200 
en buffer fosfato salino durante toda la noche. El revelado se hizo con un anticuerpo secundario policlonal de conejo marcado con peroxidasa dirigido a inmunoglobulinas de ratón y con diaminobenzidina. Se contratiñó con hematoxilina. El porcentaje de reactividad a PCNA se determinó en 15 microfotografías utilizando un analizador de imágenes asistido por computadora (Image-ProPlus 6.0).

\section{Pruebas de función hepática y marcadores de coagulación}

Bajo anestesia, se realizó en los animales punción intracardiaca para colectar sangre en tubos con ácido etilendiaminotetraacético y libre de anticoagulante; se separó suero y plasma, y se almacenó a $-70^{\circ} \mathrm{C}$ hasta su uso. Los niveles séricos de alanina aminotransferasa (ALT) y aspartato aminotransferasa (AST), así como el fibrinógeno en plasma, tiempo de tromboplastina (TP) y tiempo parcial de tromboplastina (TPT), fueron determinados en un analizador automatizado Vitros DT 60.

\section{Análisis estadístico}

Los datos se presentan como la media \pm desviación estándar (DE) para representaciones gráficas. La significancia estadística se determinó mediante ANOVA de una vía; las diferencias entre dos grupos se analizaron con la prueba de $t$ de Student. Los datos se analizaron con el software Graph Prism 7.0. Se consideró estadísticamente significativo un grado de significación $(p)<0.05$.

\section{Resultados}

\section{La terapia génica con Ad-huPA y Ad- $\triangle$ huPA revierte la fibrosis hepática}

La administración del Ad-huPA y Ad- $\triangle$ huPA revierte el tejido fibrótico entre el $48.7 \%-41.5 \%$ alcanzando el máximo efecto al día 6 postratamiento (Fig. 1). No se observaron diferencias significativas en el efecto antifibrótico entre los transgenes en ninguno de los días evaluados. Sin embargo, los hígados tratados con $\triangle$ huPA presentan menor fibrosis lobular y periportal, así como disminución en el ancho de las fibras y en la alteración histológica del tejido al avanzar los días postratamiento (día 4 y 6) en comparación con los controles.

\section{Pruebas de función hepática}

En la figura 2 se muestran los niveles de las enzimas hepáticas ALT y AST, determinadas para evaluar la funcionalidad hepática; las cuales aumentaron significativamente después de la administración de los adenovectores tanto en los controles sanos como en los animales cirróticos, con ambas formas del transgén. Dicho aumento podría deberse al efecto citotóxico del adenovirus en el tejido hepático, que está presente incluso en hígados sanos. En esta consideración, las ratas cirróticas tratadas con $\triangle$ uPA mostraron niveles más bajos en ALT y AST que las ratas cirróticas tratadas con uPA (Fig. 2), lo que puede interpretarse como una medida indirecta de los beneficios en la función hepática que el tratamiento con $\triangle$ UPA logra en hígados cirróticos.

\section{Ad- $\triangle$ huPA no altera los marcadores de coagulación}

En los animales cirróticos tratados con $\triangle$ huPA, los valores de TP, TPT y del fibrinógeno no aumentaron en comparación con los animales control, lo que indica que no hubo efectos adversos causados por la transgénesis, mientras que la terapia con Ad-huPA modificó al día 4 dichos marcadores respecto de los controles (Fig. 3). Estos resultados sugieren alteraciones en la cascada de coagulación causada por uPA silvestre en los primeros días postratamiento.

\section{El tratamiento con huPA y $\triangle$ huPA favorece la proliferación celular en el hígado}

La tinción de PCNA en hepatocitos de tejido normal fue del $53 \%$ con uPA y del $50 \%$ con $\triangle$ huPA al día 6 postratamiento (Fig. 4). Por otro lado, los hígados cirróticos mostraron un aumento del $61 \%$ en la regeneración celular después del tratamiento con el huPA silvestre y del $69 \%$ con el huPA truncado, en comparación con animales no tratados (Fig. 4). Las células positivas para PCNA se identificaron como hepatocitos con predominio al día 4 y 6 postratamiento, con diferencia significativa para el $\triangle$ huPA solo en el día 6 .

\section{Discusión}

En este estudio demostramos que la administración sistémica de Ad-huPA y Ad- $\Delta$ huPA revierte la fibrosis en un modelo de cirrosis experimental en 
A

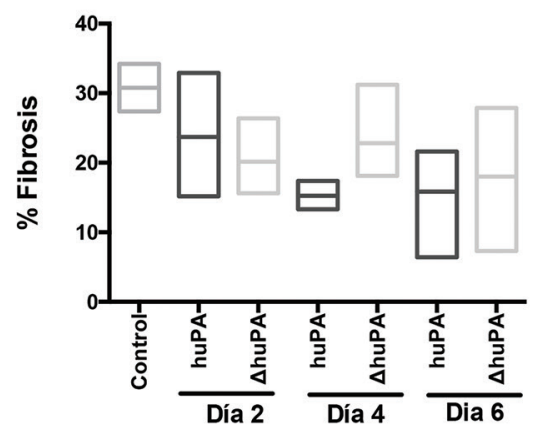

B

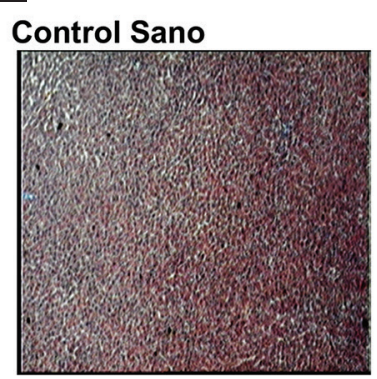

Sano + Ad

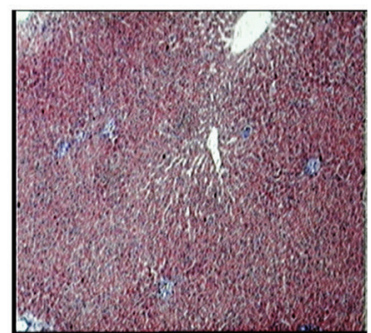

\section{Control cirrótico}

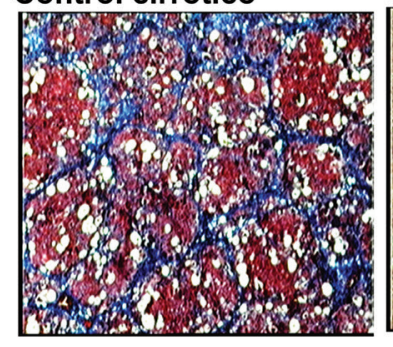

Ad-huPA

2D

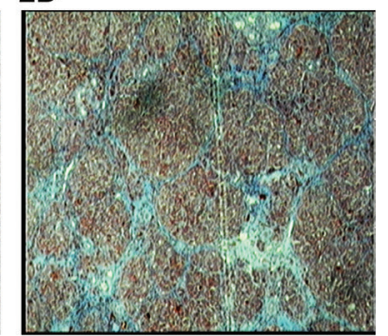

4D

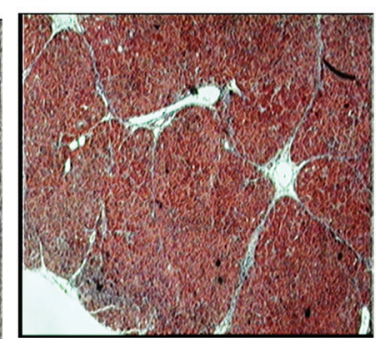

6D

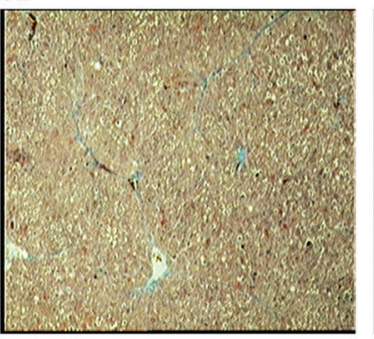

\section{Ad- $\triangle$ huPA}

2D

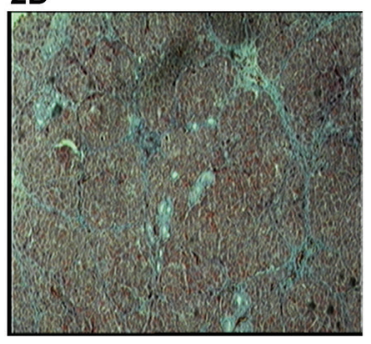

4D

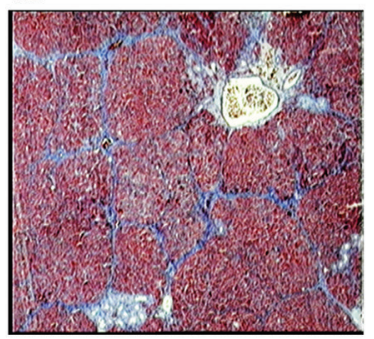

6D

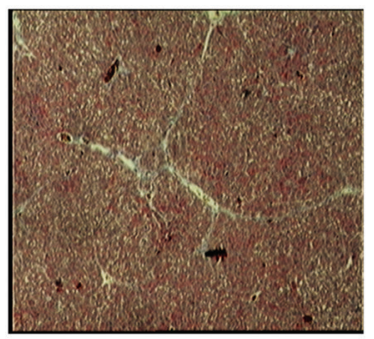

Figura 1. Porcentaje de fibrosis en tejido hepático postratamiento con vectores adenovirales Ad-huPA o Ad-AhuPA. A: porcentaje de fibrosis hepática al día 2, 4 y 6 postratamiento. La mayor disminución de tejido fibrótico se observó al día 6 con ambos transgenes. No se presentan diferencias significativas en la reversión de la fibrosis entre los transgenes. B: fotografías representativas de la tinción de muestras de hígado con tinción tricrómico de Masson (20X). En la primera columna controles de hígados sano y sano tratado con vector viral presentan predominio de componentes del parénquima. El tejido cirrótico control presenta nódulos cirróticos característicos rodeados de gruesas bandas de fibrosis que muestran una fibrosis progresiva teñida de azul. En la segunda y tercera columna, hígados de animales tratados con Ad-huPA y Ad- $\triangle$ huPA respectivamente; en ambas columnas después de 6 días del tratamiento con huPA o $\triangle$ huPA solo hay bandas de fibrosis delgadas que se extienden desde las áreas portales, así como una menor deformación tisular y esclerosis leve de la vena central.

huPA: forma silvestre del activador de plasminógeno tipo urocinasa; $\triangle$ huPA isoforma truncada del activador de plasminógeno tipo urocinasa.

niveles comparables con lo obtenido en publicaciones anteriores utilizando el Ad-huPA o el Ad- $\Delta$ huPA $^{6,7}$. Adicionalmente, los resultados del análisis morfométrico no mostraron diferencias significativas entre los grupos tratados con las diferentes formas del transgén. Las disminución del tejido fibroso aumentó a lo largo del tiempo después de la administración de los tratamientos alcanzando su pico máximo al sexto día en un rango del 41 al $48 \%$ en la reducción de la fibrosis comparado con el grupo control no 
A

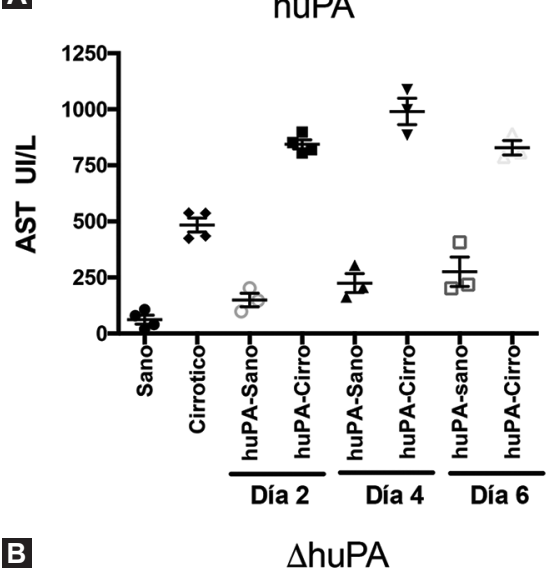

C
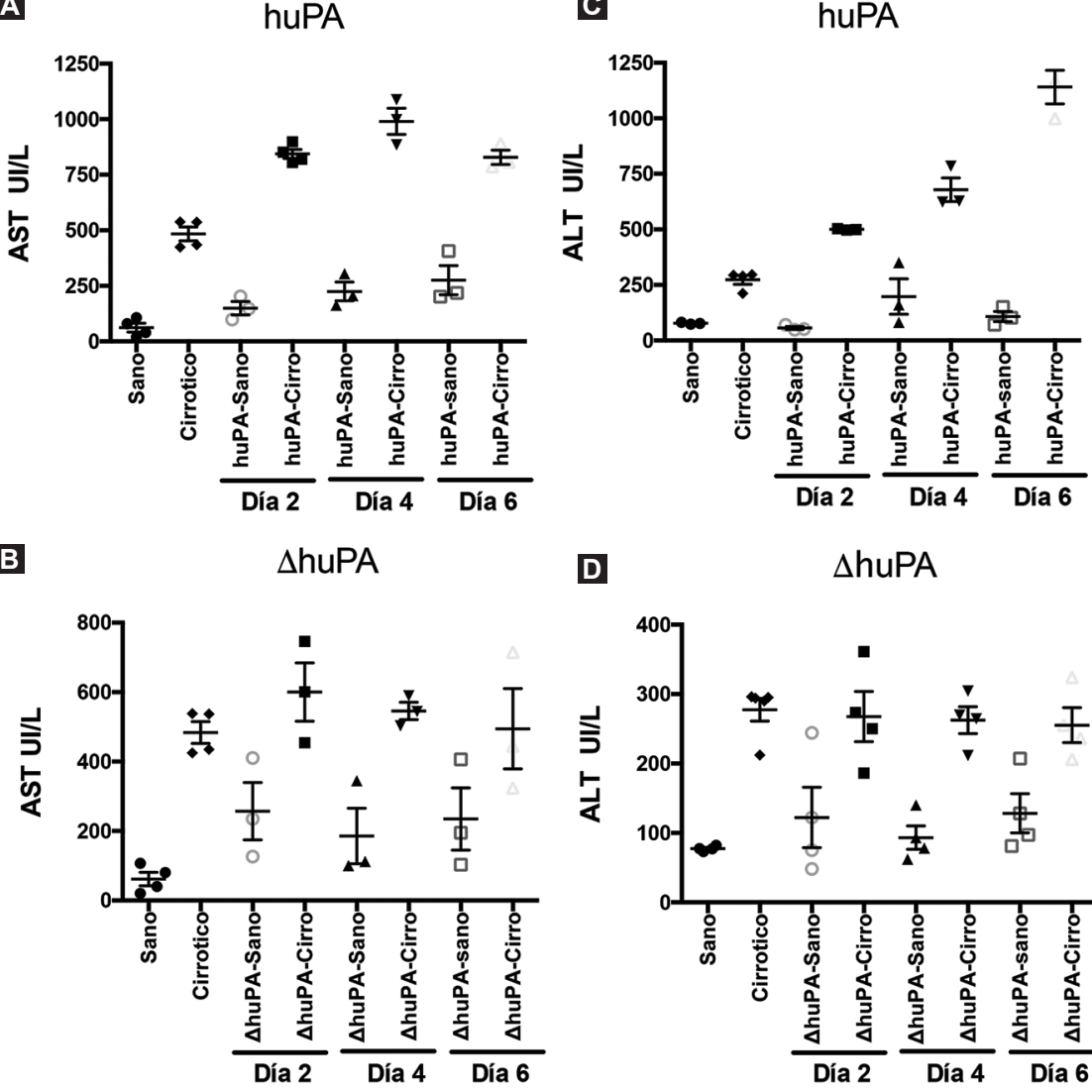

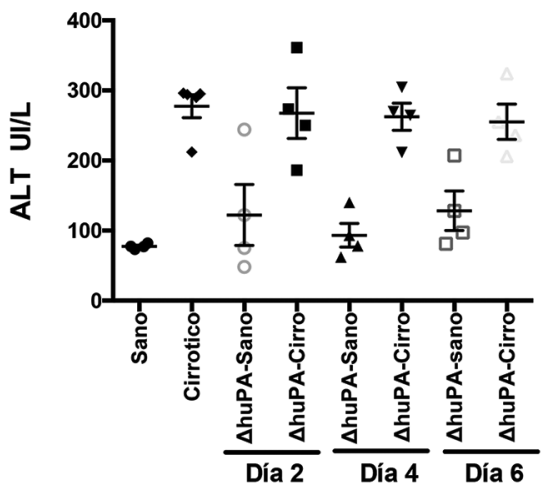

Figura 2. Niveles de enzimas hepáticas séricas (ALT y AST) postadministración de Ad-huPA o Ad- $\triangle$ huPA. A y B: niveles de AST y ALT de los controles y de los animales tratados con Ad-huPA a los distintos tiempos de corte. C y D: representación gráfica de los niveles de AST y ALT del grupo tratado con Ad- $\Delta$ huPA y sus controles. Después de la administración de los transgenes vía vena ilíaca, se realizó análisis séricos al día 2, 4 y 6; valores basales fueron monitoreados en el grupo control sin administración de adenovirus.

ALT: alanina aminotransferasa; AST: aspartato aminotransferasa; huPA: forma silvestre del activador de plasminógeno tipo urocinasa; $\triangle$ huPA isoforma truncada del activador de plasminógeno tipo urocinasa.

tratado; alcanzando una diferencia estadística al día 4 y 6 en los animales tratados con huPA y al día 6 en los animales tratados con $\triangle$ huPA $(p<0.05)$ respecto a los animales no tratados. Con el fin de corroborar los beneficios observados en la reversión del tejido fibroso, evaluamos la regeneración celular en animales sanos y cirróticos, suponiendo que las condiciones del microambiente presentes en el hígado dañado podrían favorecer una mayor respuesta en la regeneración tisular. Los resultados muestran que la regeneración celular medida por la inmunohistoquímica dirigida a PCNA aumenta con ambos tratamientos en comparación con las ratas no tratadas $(p<0.05)$, alcanzando su pico máximo el día 6 postratamiento. Sin embargo, la regeneración celular se incrementó significativamente $(p<0.05)$ en animales cirróticos en comparación con ratas normales 50 vs. $69 \%$. No obstante, tanto huPA como $\triangle$ huPA parecen aumentar de manera equiparable la regeneración de hepatocitos en animales cirróticos (Fig. 4). Este hecho puede explicarse con estudios previos que reportan el papel del factor de necrosis tumoral alfa (TNF- $\alpha$ ) y la interleucina 6 (IL-6) en la preparación de las células hepáticas para el proceso de regeneración, luego de una hepatectomía parcial ${ }^{9,10}$. Por otro lado, se ha demostrado que el plasminógeno media las propiedades reparadoras del UPA en el hígado, por lo tanto el uPA en un hígado cirrótico en combinación con la presencia de citocinas proinflamatorias en respuesta al daño puede ser parte del microambiente que brinda las condiciones óptimas para un mejor proceso de regeneración que el entorno presente en el tejido hepático sano ${ }^{11}$. Por otro lado, se conoce que los vectores adenovirales tienen tropismo para el tejido hepático cuando se administraran vía sistémica ${ }^{12}$, lo que representa una 


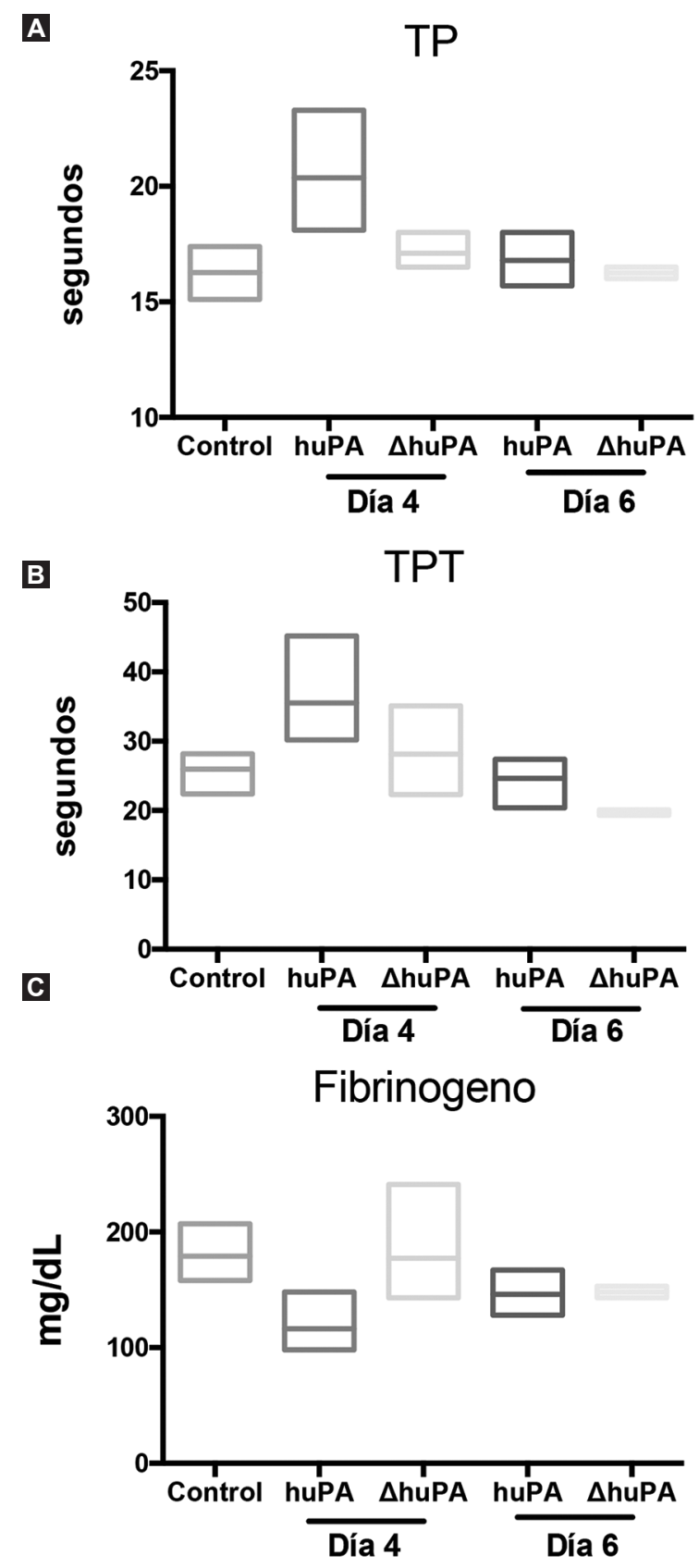

Figura 3. Evaluación de marcadores de coagulación. Determinación de marcadores de coagulación: tiempo de protrombina (TP) (A), tiempo parcial de tromboplastina (TPT) (B) y fibrinógeno (C). Se analizaron animales cirróticos tratados con Ad-huPA y Ad-ShuPA. Los valores de TP, TPT y fibrinógeno no aumentaron en los animales cirróticos tratados con $\triangle U P A$ en comparación con los animales control, lo que indica que no hay efectos adversos causados por la transgénesis, mientras que la terapia con Ad-huPA aumenta los parámetros de coagulación por encima de los controles, en particular el día 4, lo que implica un trastorno en la cascada de coagulación causada por la forma de uPA secretado.

huPA: forma silvestre del activador de plasminógeno tipo urocinasa; $\triangle$ huPA isoforma truncada del activador de plasminógeno tipo urocinasa; uPA: plasminógeno tipo urocinasa. ventaja al reducir los posibles efectos secundarios de la expresión de uPA en otros tejidos. Previamente nuestro grupo demostró que los adenovirus se dirigen de manera eficiente a hepatocitos y que pueden transducir se manera segura hígados cirróticos ${ }^{13}$. En este estudio detectamos un aumento significativo de las enzimas hepáticas ALT y AST en animales cirróticos con el tratamiento de Ad-huPA, sugiriendo daño celular que no se presenta en el tratamiento con Ad- $\Delta$ huPA. Así mismo, los animales sanos tienden a aumentar los niveles séricos de las pruebas de funcionalidad hepática con ambos tratamientos, pero de una forma menos pronunciada tras la administración de los adenovirus. Se sabe que la administración de adenovirus aumenta los niveles séricos de TNF- $\alpha$ e IL-6 y que pueden prolongar los tiempos de coagulación $n^{14}$; es importante establecer que los animales presentaron elevación de las enzimas hepáticas durante las primeras $48 \mathrm{~h}$ posteriores a la administración de adenovirus, disminuyendo entre 72 y $96 \mathrm{~h}$ postratamiento (Fig. 2) en el caso de los grupos tratados con $\triangle$ huPA. Es notable que los niveles séricos de ALT y AST fueran más bajos en los animales tratados con Ad- $\Delta$ huPA en comparación con Ad-uPA, lo que implica un efecto específico del transgén. No obstante, no se presentó mortalidad en los animales cirróticos con respecto a las ratas sanas, lo que sugiere que el daño transitorio causado por la administración del vector y el transgén puede resolverse sin mayores consecuencias.

Debido al deterioro del tejido cirrótico los animales con daño hepático podrían experimentar trastornos de la coagulación ${ }^{15}$, mismos que podrían aumentar con la administración de huPA como transgén debido a su papel en el sistema de coagulación ${ }^{3}$; por lo cual analizamos los parámetros de coagulación con el fin de monitorear posibles eventos adversos. Dado que $\triangle$ huPA es una proteína no secretada, esperábamos que su uso como transgén no representara ninguna alteración en los eventos de coagulación ${ }^{16}$. Ninguna de las formas del transgén afectó negativamente a los marcadores de coagulación evaluados, donde las diferencias en niveles del fibrinógeno, del TP y del TPT para ambos grupos Ad-huPA y Ad- $\Delta$ huPA no muestran diferencias significativas entre los controles sanos y las ratas cirróticas tratadas seis días postratamiento. Además, en el sexto día después del tratamiento, los marcadores de coagulación evaluados 

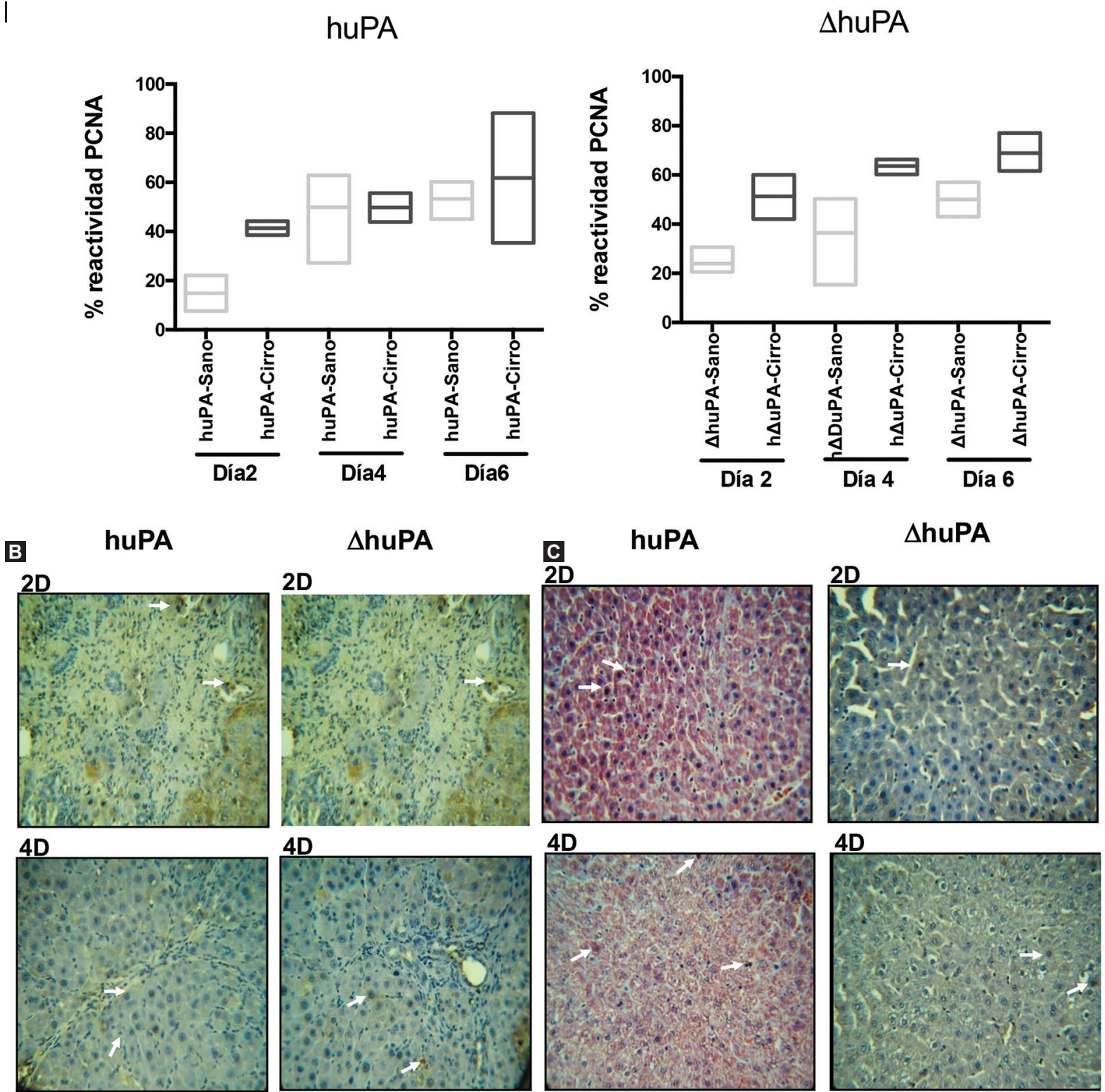

6D

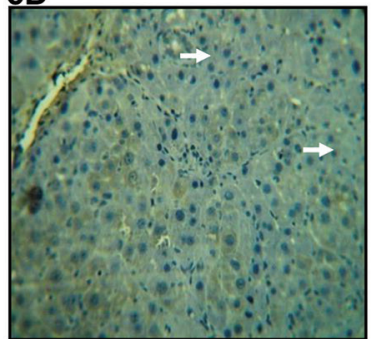

6D

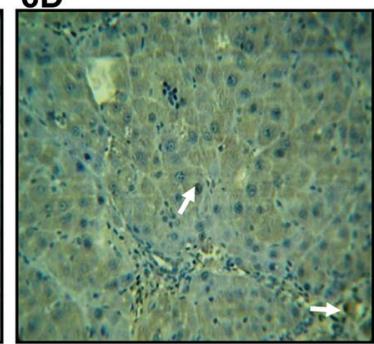

6D

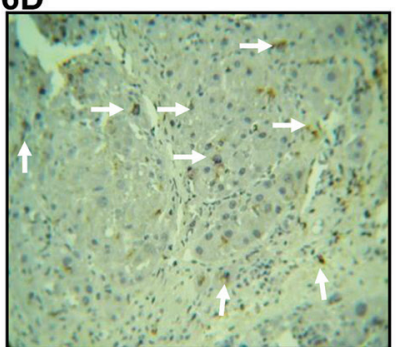

6D

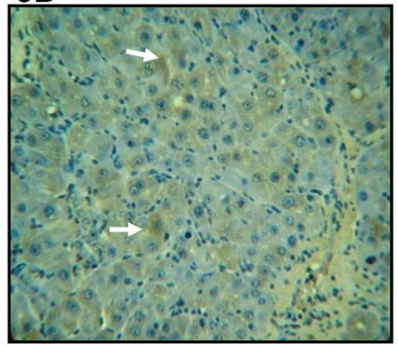

Figura 4. Análisis de proliferación celular por el marcador PCNA (antígeno nuclear de proliferación celular) postratamiento. Los núcleos en la mitosis se cuantificaron por dos patólogos independientes (40X). A: representa el porcentaje de hepatocitos teñidos con PCNA en los distintos grupos analizados; muestra un 50-53\% de positividad a PCNA en hepatocitos normales en el día 6 después de la administración de los adenovirus. B y C: los hígados cirróticos después de 6 días de tratamiento muestran abundantes núcleos teñidos positivos (flechas blancas) y figuras mitóticas en un $60-69 \%$ ( $p>0.005)$ en comparación con los animales no tratados. En las fotografías representativas $B$, las células positivas para $P C N A$ se identificaron como hepatocitos y predominan en el día 4 y 6 después del tratamiento, con una diferencia significativa para el transgén $\triangle u P A$ solo en el día $6(p>0.005)$. Se utilizaron como controles secciones de hígado cirrótico sin administración de adenovirus. Las medidas tuvieron una variación del $3 \%$ entre los dos patólogos diferentes.

$\triangle U P A$ : isoforma truncada del plasminógeno tipo urocinasa. 
alcanzaron los niveles basales presentes en los animales sanos no tratados.

\section{Conclusiones}

Basados en estos resultados observados, se sugiere que la transgénesis usando huPA o $\triangle$ huPA se puede emplear como tratamiento antifibrótico sin temor a inducir un trastorno de coagulación severo, incluso si se administra en animales cirróticos.

\section{Financiamiento}

Este proyecto no cuenta con financiamiento directo.

\section{Conflicto de intereses}

Los autores declaran la ausencia de conflicto de intereses respecto a esta publicación.

\section{Responsabilidades éticas}

Protección de personas y animales. Los autores declaran que los procedimientos seguidos se conformaron a las normas éticas del comité de experimentación humana responsable y de acuerdo con la Asociación Médica Mundial y la Declaración de Helsinki.

Confidencialidad de los datos. Los autores declaran que en este artículo no aparecen datos de pacientes.

Derecho a la privacidad y consentimiento informado. Los autores declaran que en este artículo no aparecen datos de pacientes.

\section{Bibliografía}

1. Macias-Barragan J, Sandoval-Rodríguez AS, Navarro-Partida J, Armendariz-Borunda J. The multifaceted role of pirfenidone and its novel targets. Fibrogenesis Tissue Repair. 2010;3:16.

2. Seki E, Brenner DA. Recent advancement of molecular mechanisms of liver fibrosis. J Hepatobiliary Pancreat Sci. 2015;22:512-8.

3. Drixler TA, Vogten JM, Gebbink MFBG, Carmeliet P, Voest EE, Borel Rinkes IHM. Plasminogen mediates liver regeneration and angiogenesis after experimental partial hepatectomy. Br J Surg. 2003;90:1384-90.

4. Herren T, Swaisgood C, Plow EF. Regulation of plasminogen receptors. Front Biosci. 2003:8:d1-8.

5. González@Cuevas J, Bueno[Topete M, ArmendarizロBorunda J. Urokinase plasminogen activator stimulates function of active forms of stromelysin

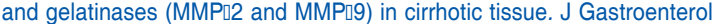
Hepatol. 2006;21:1544-54

6. Salgado S, Garcia J, Vera J, Siller F, Bueno M, Miranda A, et al. Liver cirrhosis is reverted by urokinase-type plasminogen activator gene therapy. Mol Ther. 2000;2:545-51.

7. Meza-Rios A, García-Benavides L, García-Bañuelos J, Salazar-Montes A, Armendáriz-Borunda J, Sandoval-Rodríguez A. Simultaneous administration of ADSCs-based therapy and gene therapy using Ad-huPA reduces experimental liver fibrosis. PLoS One. 2016;11:e0166849.

8. Armendariz-Borunda J, Bastidas-Ramírez BE, Sandoval-Rodríguez A González-Cuevas J, Gómez- Meda B, García-Bañuelos J. Production of first generation adenoviral vectors for preclinical protocols: amplification, purification and functional titration. J Biosci Bioeng. 2011;112:415-21.

9. Streetz K, Luedde T, Manns M, Trautwein C. Interleukin 6 and liver regeneration. Gut. 2000;47:309-12.

10. Campbell JS, Prichard L, Schaper F, Schmitz J, Stephenson-Famy A, Rosenfeld ME, et al. Expression of suppressors of cytokine signaling during liver regeneration. J Clin Invest. 2001;107:1285-92.

11. Shanmukhappa K, Sabla GE, Degen J, Bezerra JA. Urokinase-type plasminogen activator supports liver repair independent of its cellular receptor. BMC Gastroenterol. 2006;6:40.

12. Hendrie PC, Russell DW. Gene targeting with viral vectors. Mol Ther. 2005;12:9-17.

13. Garcia-Bañuelos J, Siller-Lopez F, Miranda A, Aguilar LK, Aguilar-Cordova E, Armendariz-Borunda J. Cirrhotic rat livers with extensive fibrosis can be safely transduced with clinical-grade adenoviral vectors. Evidence of cirrhosis reversion. Gene Ther. 2002;9:127-34.

14. Smith JS, Tian J, Lozier JN, Byrnes AP. Severe pulmonary pathology after intravenous administration of vectors in cirrhotic rats. Mol Ther. 2004;9:932-41.

15. O'Leary JG, Greenberg CS, Patton HM, Caldwell SH. AGA Clinical practice update: coagulation in cirrhosis. Gastroenterology. 2019;157:34-43.

16. Lieber A, Peeters MJ, Gown A, Perkins J, Kay MA. A modified urokinase plasminogen activator induces liver regeneration without bleeding. Hum Gene Ther. 1995;6:1029-37. 